\title{
An Investigation of the Effects of Holographic Wristbands on Strength, Balance and Flexibility - a Double-Blind Placebo Controlled Study
}

\author{
ZÜbeyir SARi, PT, PhD ${ }^{1)}$, Nilüfer Kablan, PT, MSc${ }^{1)}$, Bahar ÖZGül, PT, MSc ${ }^{1)}$, \\ Onur AydoĞdu, $\mathrm{PT}^{1)}$, Eren Timurtaș, $\mathrm{PT}^{1)}$, FAtih TÜtÜnCÜOĞLu, $\mathrm{PT}^{2)}$, \\ Saadet Ufuk Yurdalan, PT, $\mathrm{PhD}^{1)}$, Mine Gülden Polat PT, $\mathrm{PhD}^{1)}$ \\ 1) Marmara University, Health Sciences Faculty, Physiotherapy and Rehabilitation Department, \\ Istanbul, Turkey,34846,TEL:+90 2163999371,FAX: +90 2163996242,E-mail:fztzubeyir@yahoo.com \\ 2) Yılduz Çocuk Private Education and Rehabilitation Center
}

\begin{abstract}
Purpose] This study investigated the effects of holographic wristbands on strength, balance and flexibility. [Subjects and Methods] The study included 43 healthy university students, 15 females (34.88\%) and 28 males (65.12\%), attending the Department of Physiotherapy and Rehabilitation at Marmara University. The age of the participants ranged from 19 to 27 (mean age $21.2 \pm 1.7$ years). Strength, balance with eyes open, balance with eyes closed and flexibility were evaluated under four different conditions of wearing holographic $E F X ®, P W X ®$ and placebo wristbands, and no wristband. [Results] In evaluations of strength, balance with eyes are open, balance with eyes closed and flexibility, a significant difference was observed in favor of the placebo wristband compared to the $P W X{ }^{\circledR}$ wristband. For the other tests, holographic wristbands had no effect on strength, flexibility or balance with eyes closed. [Conclusion] It was concluded that holographic wristbands, which are marketed asergogenic aids, have no effect on strength, balance or flexibility.

Key words: Holographic technology, Wristband, Balance
\end{abstract}

(This article was submitted Jan. 13, 2012, and was accepted Feb. 18, 2012)

\section{INTRODUCTION}

Athletes often use products that enhance, or are believed to enhance, physical performance $\$$. Many products are marketed as ergogenic aids despite the lack of evidence to support these assertions $\$$. An "ergogenic aid" is defined as any means of enhancing energy utilization, including energy production, control, and efficiency. Ergogenic aids are substances or devices that enhance energy production, use or recovery and provide athletes with a competitive advantage p. $_{\text {. }}$.

Ergogenic aids are classified into five categories generally involving mechanical, psychological, physiological, pharmacological and nutritional aids $\$$. While some of these aids have been shown to effect performance when used in

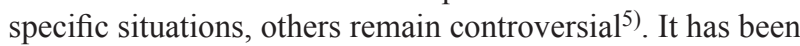
suggested that the placebo effect plays a major role in the benefits claimed for some ergogenic aids 9 . McClung et al. also reported that the placebo effect contributed significantly to performance.

Products incorporating hologram technology have recently been widely marketed as ergogenic products ${ }^{\circ}$. Holographic wristbands from various manufacturers are widely available ${ }^{8-11}$. Holograms placed in $E F X{ }^{\circledR}$ wristbands are claimed to stimulate the electrical frequency integrated within it and the movement of positive and negative free ions, to open the energy channels of the body, and to reload the balance of the body, thereby positively affecting balance, strength, flexibility and range of joint motion $\$$. On the other hand, $P W X{ }^{\circledR}$ brand holographic wristbands from a different manufacturer are claimed to contain algorithms and frequencies that positively affect cellular energy domains in humans due to their holographic technology and negative ion production properties. This brand of wristband is also claimed to relieve joint and muscle pain, improve blood circulation, reduce swelling, and maintain muscle fitness and flexibility, making users more vigorous and resistant to stress, and therefore more agile $\mathrm{p}$.

The aim of the present study was to investigate the effectiveness of $E F X ®$ and $P W X \AA$ brand holographic wristbands on muscle strength, flexibility and balance.

\section{SUBJECTS AND METHODS}

A total of 43 university students, 15 females and 28 males participated in this study. The mean age of the participants was $21.26 \pm 1.77$ years, and none had any orthopedic or neurologic problems or any history of falling within the previous month. The study was approved by the Ethics Committee of Marmara University, Faculty of Medicine Research (Approval date: 07.04.2011; Protocol no: 09.2011.0077). The study was carried out at Marmara University, Faculty of Health Sciences. Potential participants were informed about the aim and method of the study. Volunteers were evaluated 
and consented to participation in the study.

Date of birth, gender, height, body weight and dominant side were recorded for all participants. Physiotherapists informed the participants about the tests during the evaluations. None of the participants had ever used the brand wristbands before, and they were ignorant of the claims made about holographic wristbands.

The evaluations were performed with no wristband, with a placebo wristband, with the $P W X{ }^{\circledR}$ brand wristband and with the $E F X ®$ brand wristband using a double-blind controlled design. Sit and reach test, grip strength and balance tests with eyes open and closed were repeated 3 times while each participant wore no wrist band, a placebo wristband or the two different brand holographic wristbands. All evaluations were made within a day, with 5-minute breaks between the wristband wearing conditions, which were chosen at random. The same physiotherapist conducted each evaluation in order to standardize the procedure. The wristband was worn on the dominant wrist during the evaluations. The evaluations were performed for all participants.

The Sit and Reach Test was performed to evaluate hamstring flexibility ${ }^{12}$. A standard test box was used for the sit and reach test (length $35 \mathrm{~cm}$, width $45 \mathrm{~cm}$, height $32 \mathrm{~cm}$; top surface $55 \mathrm{~cm}$ long and $45 \mathrm{~cm}$ wide). Participants were asked to sit on the floor and rest the soles of their feet evenly on the test box. They were then asked to bend forward from the torso and to reach forward using their hands without bending their knees. The section where the soles rested on the test box was accepted as "point-zero" and the farthest point reached by the third fingers was measured in $\mathrm{cm}$. The test was repeated three times and the maximum reach distance was recorded.

A Jamar ${ }^{\circledR}$ hand dynamometer was used at the second width setting to measure the dominant hand grip-strength of the participants. The measurement was conducted with the participant in a sitting position, with the shoulder in adduction and the neutral position, the elbow in $90^{\circ}$ flexion, and the forearm and wrist in the neutral position. The measurements were repeated three times and the maximum value was recorded 13 .

Balance tests with and without the wristband specified in the brochures of the $E F X \AA$ and $P W X \AA$ wristbands were used The participants were tested with their eyes open and closed. With their arms at $90^{\circ}$ abduction and the non-dominant hip and knee in flexion, maximum force was applied to the non-dominant arm and the value at the moment when the participant lost balance was recorded using a J-Tech ${ }^{\circledR}$ Commander myometer. The measurements were repeated three times and the maximum value was recorded.

SPSS (version 11.5 for Windows) was used for statistical analysis. Repeated measures analysis of variance (ANOVA) was used to investigate the effects of wristbands on strength, balance and flexibility. Bonferroni correction was applied for dual comparisons between the groups.

A value of $p<0.05$ was considered as statistically significant. The results are expressed as the arithmetic mean \pm standard deviation $(\mathrm{X} \pm \mathrm{SD})$
Table 1. Physical characteristics of participants

\begin{tabular}{lc}
\hline & $\mathrm{X} \pm \mathrm{SD}$ \\
\hline Age (year) & $21.2 \pm 1.7$ \\
Height (meter) & $1.7 \pm 0.9$ \\
Body Weight (kilogram) & $66.2 \pm 10.5$ \\
\hline
\end{tabular}

\section{RESULTS}

A total of 43 university students, 15 females and 28 males, were included in this study. The mean age of the participants was $21.2 \pm 1.7$ years (Table 1 ).

Strength, balance and flexibility were evaluated under the four different conditions of wearing holographic $E F X \circledR$ and $P W X ®$ wristbands, a placebo wristband and no wristband. Strength, balance with eyes open, balance with eyes closed and flexibility were analyzed via repeated measures ANOVA and a significant difference was found only in the evaluation of balance with eyes open (Table 2, $\mathrm{p}<0.05$ ). Holographic wristbands were found to have no effect on strength, flexibility and balance with eyes closed (Table 2, $\mathrm{p}>0.05$ ).

Dual comparison of the balance with eyes open using the Bonferroni correction revealed that balance was better when the placebo wristband was worn than when the $P W X{ }^{\circledR}$ wristband (Table 3, $\mathrm{p}<0.05$ ). However, there was no statistical difference between the conditions in which the $E F X{ }^{\circledR}$ wristband and the $P W X{ }^{\circledR}$ wristband were worn during evulation of balance with eyes open.

\section{DISCUSSION}

We found that wearing $E F X \AA$, and $P W X{ }^{\circledR}$ wristbands made no difference to strength, balance with eyes closed and flexibility. The only significant difference found was in the balance with eyes open condition. It was found that balance was better when a placebo wristband was worn than when the $P W X{ }^{\circledR}$ wristband was worn. McClung and Collins $\$$ also reported that the placebo effect of ergogenic aids improved performance in sports and activities. Therefore, one of the first considerations about the use of holographic wristbands involves whether these products have a placebo effect and whether this effect is reflected in sports and other activities ${ }^{14}$. Although these studies have suggested investigating whether the holographic wristbands have placebo effects on human performance, the results of our study do not indicate with certainty that the placebo effect had an influence on balance performance because the comparison was between the placebo wristband and the PWX ${ }^{\circledR}$ wristband. In addition, no significant differences were found between the wearing of placebo wristband and the EFX ${ }^{\circledR}$ wristband or no wristband in the balance with eyes open condition. Therefore, further studies investigating the placebo effect on human performance of holographic wristbands are needed.

There is increased use each year of holographic wristbands as an ergogenic aid among the general population 4 . However, a review of the literature found no evidence-based study demonstrating improved performance through the use 
Table 2. Mean and standard deviations of parameters of all the tests

\begin{tabular}{|c|c|c|c|c|}
\hline & & Mean \pm SD & $\mathrm{F}$ & $\mathrm{p}$ \\
\hline \multirow{4}{*}{ Strength } & $\mathrm{EFX}{ }^{\circledR}$ & $39.79 \pm 2.26$ & \multirow{4}{*}{0.057} & \multirow{4}{*}{0.982} \\
\hline & $\mathrm{PWX}{ }^{\circledR}$ & $39.69 \pm 1.96$ & & \\
\hline & Placebo & $39.44 \pm 2.19$ & & \\
\hline & No wristband & $39.97 \pm 2.12$ & & \\
\hline \multirow{4}{*}{ Balance with eyes open } & EFX® & $118.860 \pm 6.53$ & \multirow{4}{*}{3.833} & \multirow{4}{*}{$0.011^{*}$} \\
\hline & $\mathrm{PWX}{ }^{\circledR}$ & $113.093 \pm 5.92$ & & \\
\hline & Placebo & $123.791 \pm 6.09$ & & \\
\hline & No wristband & $115.512 \pm 6.07$ & & \\
\hline \multirow{4}{*}{$\begin{array}{l}\text { Balance with eyes } \\
\text { closed }\end{array}$} & $\mathrm{EFX}{ }^{\circledR}$ & $103.488 \pm 4.61$ & \multirow{4}{*}{0.542} & \multirow{4}{*}{0.466} \\
\hline & $\mathrm{PWX}{ }^{\circledR}$ & $102.395 \pm 4.19$ & & \\
\hline & Placebo & $104.209 \pm 4.47$ & & \\
\hline & No wristband & $100.326 \pm 3.94$ & & \\
\hline \multirow{4}{*}{ Flexibility } & $\mathrm{EFX} ®$ & $8.465 \pm 1.33$ & \multirow{4}{*}{0.056} & \multirow{4}{*}{0.983} \\
\hline & $\mathrm{PWX}{ }^{\circledR}$ & $8.605 \pm 1.25$ & & \\
\hline & Placebo & $8.512 \pm 1.37$ & & \\
\hline & No wristband & $8.465 \pm 1.33$ & & \\
\hline
\end{tabular}

Table 3: Balance with eyes open in all conditions

\begin{tabular}{llc}
\hline & & Mean Difference \pm Std. Error \\
\hline EFX ${ }^{\circledR}$ & PWX ${ }^{\circledR}$ & $5.767 \pm 3.032$ \\
& Placebo & $-4.930 \pm 3.049$ \\
& No Wristband & $3.349 \pm 3.264$ \\
\hline PWX ${ }^{\circledR}$ & EFX & $-5.767 \pm 3.032$ \\
& Placebo & $-10.698 \pm 3.366^{*}$ \\
& No Wristband & $-2.419 \pm 3.607$ \\
\hline PLACEBO & EFX® & $4.930 \pm 3.049$ \\
& PWX ${ }^{\circledR}$ & $10.698 \pm 3.366^{*}$ \\
& No Wristband & $8.279 \pm 3.705$ \\
\hline No Wristband & EFX ${ }^{\circledR}$ & $-3.349 \pm 3.264$ \\
& PWX & $2.419 \pm 3.607$ \\
& Placebo & $-8.279 \pm 3.705$ \\
\hline
\end{tabular}

of holographic wristbands. Brice et al. analyzed the effects of holographic wristbands on balance and stability performance using a posturography method and reported that placebo and holographic wristbands elicited no changes in balance 9 . Similarly, our study found that $E F X ®$ and $P W X ®$ wristbands had no effect on balance with eyes closed. Unlike the study of Brice et al. 9 , we evaluated balance using a myometer rather than posturography.

Since the manufacturers of $E F X ®$ and $P W X{ }^{\circledR}$ wristbands claim that these wristband have positive effects on balance, strength and flexibility 9 , we also investigated the effects of placebo and other wristbands on flexibility and grip strength in addition to balance. We found that placebo and other wristbands had no effect on flexibility and grip strength. This evaluation did find that the use of wristbands affected balance with eyes open; however balance was better with the placebo wristband than with the $P W X{ }^{\circledR}$ wristband. Similar to the study of Brice et al. $\$$, the present results reveal that the holographic wristbands had no effects on grip strength and flexibility. Since a review of the literature found no relevant studies apart from that of Brice et al. 5 , there was no opportunity to compare our results with other studies. The present study is therefore of significance, as the literature contains a very limited body of research in this field. Holographic wristbands are also available from other manufacturers and future studies might compare their effects with those of the $E F X{ }^{\circledR}$ and $P W X \AA$ wristbands.

Our study evaluated the short-term effects of holographic wristbands. The study was limited in that the long-term effects of holographic wristbands were not investigated. Future studies should investigate the potential long-term effects of holographic wristbands. Furthermore, the potential 
effects of holographic wristbands should also be investigated using individuals with balance problems rather than healthy subjects.

In conclusion, in the present study, it was found that $E F X ®$ and $P W X{ }^{\circledR}$ holographic wristbands had no effects on balance, strength and flexibility.

\section{REFERENCES}

1) Tokish JM, Kocher MS, Hawkins RJ: Ergogenic Aids: A Review of Basic Science, Performance, Side Effects, and Status in Sports. Am J Sports Med, 2004, 32: 1543-1553. Medline [CrossRef

2) Juhn M: Popular sports supplements and ergogenic aids. Sports Med, 2003, 33: 921-939. Medline CrossRef

3) Silver MD: Use of ergogenic aids by athletes. J Am Acad Orthop Surg, 2001, 9: 61-70. Medline

4) Ahrendt DM: Ergogenic aids: counseling the athlete. Am Fam Physicians, 2001, 63: 913-922. [Medline]

5) Thein LA, Thein JM, Landry GL: Ergogenic Aids. Phys Ther, 1995, 75: 426-439. [Medline]

6) Brice SR, Jarosz BS, Ames RA, et al.: The effect of close proximity holographic wrist bands on human balance and limits of stability: A randomised, placebo-controlled trial. J Bodyw Mov Ther, 2011, 15: 298-303. Medline CrossRef

7) McClung M, Collins D: "Because I know it will!": placebo effects of an ergogenic aid on athletic performance. J Sport Exerc Psychol, 2007, 29: 382-394. Medline

8) Performance EF: What is EFX? What is EFX holographictechnology? http://www.efx.com.tr/tr/default.asp?rsm=141000000000 (Accessed Sep. 18, 2010).

9) Powerx Store: How does it work? http://www.pwxstore.com/syf/nasilcalisir.html (Accessedseptember 18, 2010).

10) Powerbalance is performancetechnology. http://www.powerbalance.com/ powerbalance (Accessed Sep. 18, 2010).

11) U-balance: http://ubalanceturkiye.com/ (Accessed Sep. 18, 2010).

12) American College of Sport Medicine: Guidelines for exercise testing and prescription. 6th ed. Baltimore: Lippincott, Williams \& Wilkins Press, 2000, pp 85-88.

13) Härkönen R, Purtomaa M, Alaranta H: Grip strength and hand position of the dynomometer in 204 Finnish adults. J Hand Surg [Br], 1993, 18: 129-132. [Medline] [CrossRef]

14) Bohannon RW: Reference values for extremity muscle strength obtained by hand-held dynamometry from adults aged 20 to 79 years. Arch Phys Med Rehabil, 1997, 78: 26-32. [Medline [CrossRef] 